\title{
EVALUATION OF BONE QUALITY AND QUANTITY BY USING BOVINE XENOGRAFT VERSUS B-TCP FOR MAXILLARY SINUS AUGMENTATION: A RANDOMIZED CONTROLLED CLINICAL TRIAL
}

\author{
Saleh Ahmed Saleh Ahmed Bakry*
}

\begin{abstract}
Purpose: Dental rehabilitation of partially or totally edentulous patients with dental implants has become a routine treatment in the last decades. However, unsuitable local conditions of the alveolar ridge, due to atrophy, gingival disease, and trauma sequelae, may provide inadequate bone volume or unfavorable vertical, horizontal, and sagittal intermaxillary relationships, which may render dental implant placement impossible or incorrect from a functional and esthetic viewpoint. Different bone graft materials have been used for sinus augmentation.
\end{abstract}

Aim: The aim of the study was to evaluate bone quality and quantity by using bovine xenograft versus $\beta$-TCP in open maxillary sinus augmentation.

Patients and methods: A total of 12 sinus (in 12 patients) were randomly divided into 2 groups. For group A patients received open sinus augmentation with xenograft (Tutobone) while patients in group B received open sinus augmentation with $\beta$-TCP. After 6 months, a second cone beam C.T was performed for each patient and compared to the first cone beam to evaluate bone quantity. A core biopsy was taken at the time of implant placement at 6 month of healing period for histological and histomorphometric evaluation of bone quality.

Results: Histological results showed that most of the particles of the two biomaterials were surrounded by new bone. The histomorphometry showed characteristics of new bone formation around the grafted particles in both groups.

Conclusion: $\beta$-TCP showed superior bone quality and quantity compared to bovine xenograft for sinus augementation.

KEYWORDS: Maxillary sinus, Xenograft, $\beta$-TCP.

\footnotetext{
* Assistant Professor of Oral and Maxillofacial Surgery, Faculty of Oral and Dental Medicine, Cairo University.
} 


\section{INTRODUCTION}

The maxillary posterior edentulous region presents a challenging condition in implant dentistry when compared to other areas of the mouth as the process of ridge resorption is bidirectional (1). The loss of upper posterior teeth results in an initial reduction in bone width at the expense of the labial bony plate at a more rapid rate than any other regions of the jaws. This is associated with remarkable vertical bone loss cause by maxillary sinus pneumatization. The resorption process is accelerated by the loss of vascularization of alveolar bone and the existing fine trabecular bone type ${ }^{(2,3)}$.

Reconstruction of posterior maxillary bone volume has been achieved by different procedures such as onlay grafts, Le Fort I osteotomies and sinus lift ${ }^{(4-6)}$ surgeries. Maxillary sinus augmentation is considered one of the most useful procedures for augmenting bone in the posterior maxilla. It was first presented by Tatum in the mid-1970s. ${ }^{(7,8)}$.

An ideal maxillary sinus bone grafting material should provide osteoinduction, osteoconduction and volume stability ${ }^{(9,10)}$. Autogenous bone represented for years the gold standard in bone grafting procedures for its osteogenic, osteoinductive and osteoconductive properties. On the other hand, its availability is limited by the little amount of intra oral graft sites, unpredictable resorption and the morbidity due to the need of a double surgical site. This has prompted the researchers to develop alternative procedures using bone substitutes ${ }^{(\mathbf{1 1}-14)}$.

Different grafting materials (as xenograft and alloplast) are have always been studied as an alternative for autogenous bone in maxillary sinus floor augmentation procedures. In this type of surgery, it should always be a priority to reduce patient morbidity to a minimum. Moreover, bone substitutes are potentially available in unlimited amounts, in different sizes and shapes. ${ }^{(15,16)}$.

Xenograft materials have been widely used in maxillary sinus lifting. They are derived from animals of various species (mostly from bovine origin). Anorganic bovine bone is one of the most widely used xenografts because of its similarity to human. It shows high biocompatibility, osteoconductivity and volumetric stability when used in sinus floor augmentation procedures ${ }^{(17,18)}$.

On the other hand, it has been suggested that the use of demineralized bone or that of bovine origin leads to ethical problems due to the theoretical risk of cross infection transmission. For this reason, different osteoconductive synthetic materials have been developed. ${ }^{(19-21)}$ Much researches has been dedicated to bone alternatives, including the purely synthetic materials such as the calcium phosphates, the hydroxyapatites, the tricalcium phosphates (TCPs) $\left(\alpha-\right.$ and $\beta$-TCP). ${ }^{(22,23)}$ Some of the calcium phosphates, such as the hydroxyapatites are nonresorbable or partially resorbable, while the $\beta$-TCP is resorbable. The use of resorbable materials is preferred since they will be in the long term replaced by bone, which is able to adapt to the loads it is exposed to. ${ }^{(24)}$

Tricalcium phosphate $\left[\mathrm{Ca}_{3}\left(\mathrm{PO}_{4}\right)^{2}\right]$, a synthetic bone-promoting biomaterial, has been applied and investigated as a biodegradable bone replacement for repair of different shapes and sizes of bone defects, due to its good biocompatibility and osteointegrative property.(25) It is generally considered that TCP is highly osteoconductive but not osteoinductive. $^{(26-30)}$ As it allows osteoprogenitor cells to grow on its surface or into its porosity and differentiate into osteoblasts, thus bringing about bone deposition. ${ }^{(31)}$ Moreover, it has been suggested that the graft material should be impregnated with the patient's blood. It has been demonstrated that the $\beta$-TCP crystals can preserve the integrity of blood cells and, hereby, the graft can gain some osteoinductive properties. ${ }^{(32)}$

The aim of this study was to evaluate bone quality and quantity by using different graft materials for maxillary sinus augmentation histologically and histomorphometrically. 


\section{PATIENTS AND METHODES}

\section{Study Design}

This was a randomized controlled clinical trial conducted on 12 maxillary sinuses in 12 patients. The sinus was randomly dived into 2 groups according to the graft materials. Group A received sinus augmentation with xenograft (Tutobone, RTI Biologics ${ }^{\mathrm{TM}}$ Tutogen medical GmbH, Germany) and Group B received sinus augmentation with $\beta$-TCP (Bioresorb classic - Herrlichkeit 4.28199 Bermen - Germany). The sudy was conducted in Faculty of Dentistry, Cairo University.

The Ethics Committee of the Faculty of Dentistry, Cairo University approved the protocol, and a detailed informed written consent including the details of surgery and the possible complications was obtained from all patients.

\section{Eligibility Criteria}

The selected patients had missing posterior maxillary teeth with insufficient available bone height (less than $5 \mathrm{~mm}$ in bone height) for implant placement indicating the need for maxillary sinus floor augmentation before implantation.

The patients included in the study fulfilled the following criteria:

- Patients with missing posterior bilateral maxillary teeth with insufficient available bone for implant placement indicating the need for maxillary sinus floor augmentation before implantation.

- Patients should be free from any systemic disease that may affect normal healing of bone, and predictable outcome.

- Normal complete blood count (CBC).

- Patients should be free from any sinus disease that might affect the health and integrity of the sinus lining.

- Non-smokers.

\section{Randomization}

The patients were allocated randomly in the two groups using allocation ratio $1: 1$. The randomization was performed using 12 opaque envelopes, 6 for group A and 6 for group B.

\section{Preoperative Preparation}

At the initial visit, all patients underwent a clinical and occlusal examination and digital panoramic radiographs were obtained to determine the residual alveolar bone height. It also helps for detection of any remaining roots or bony pathoses in the posterior maxillary region. Maxillary sinus was examined for any opacities or prominent sinus septa.

A total of 26 implants were inserted in the augmented sites. There were 6 specimens evaluated for each biomaterial. A total of 12 specimens were retrieved and evaluated.

\section{Surgical method}

Immediately before surgery the patient was allowed to rinse with Chlorohexidine Gluconate $0.1 \%$ mouth wash (Antiseptol, Kahira Pharma Co, Cairo, Egypt.). All surgical procedures were performed under local anesthesia (Articane $4 \%$ with 1: 100000 epinephrine, Ubistesin ${ }^{\mathrm{TM}}$ forte, $3 \mathrm{M}$ ESPE, Germany.) using maxillary nerve block with buccal infiltration. Maxillary sinus floor elevation was performed using lateral window technique. A mucosal crestal incision was performed with anterior releasing incisions and a full-thickness flap was reflected to expose the lateral wall of the sinus. A round diamond bur (sinus bur) was used to delineate the outline of the antrum on the lateral wall of the maxilla. Once the outline was completed, special elevators (surgical sinus freers) were used to gently push the sinus membrane inward. As the dissection continued, the membrane was elevated from the floor, lateral wall, medial wall and anteroposteriorly to provide a large compartment for graft placement. 
The grafting materials packed in the sinus cavity under the lifted membrane especially in the posterior and anterior parts and a resorbable collagen membrane (Biocollagen, Bioteck, Italy) was positioned to cover the graft material and the lateral window. The mucoperiosteal flap was repositioned and sutured with 000 vicryl suture material.

For group A, the Bovine xenograft (Tutobone, RTI Biologics ${ }^{\mathrm{TM}}$ Tutogen medical GmbH, Germany) packed in the sinus cavity under the lifted membrane especially in the posterior and anterior parts. For group B, the $\beta$-TCP (Bioresorb classic - Herrlichkeit 4.28199 Bermen - Germany) packed in the sinus cavity under the lifted membrane especially in the posterior and anterior parts. Postoperatively, the patients were instructed to use extraoral ice packs for the first postoperative six hours. Non-steroidal anti-inflammatory analgesic (Diclofenac potassium 50mg, Catafast $50 \mathrm{mg}$ tablets, Novartis Pharma AG, Cairo, Egypt.) was prescribed three times daily for three days. Antibiotic (clindamycin $300 \mathrm{mg}$, Clindam 300 mg capsules, Sigma pharmaceutical industries, Egypt) was prescribed three times daily for five days. The mouth wash was started 24 hours after surgery 3 times a day for 1 week.

The patients instructed to avoid creation of negative pressure as blowing the nose, suckling through a straw, and sneezing (if it occurs, should be done with the mouth open). All patients were recalled 1 week; 1,3 , and 6 months postoperatively for clinical evaluation. The clinical evaluation included assessment of complications during surgery and postoperative healing (inflammation and wound dehiscence). Postoperative cone beam $\mathrm{CT}$ radiographs were taken for every patient 1 week $\left(\mathrm{T}_{0}\right)$ and 6 months $\left(\mathrm{T}_{6}\right)$ postoperatively (Figures 1 and 2). The radiographs were made with the same machine and same exposure parameters (Scanora3D, Sorredex- Finland, 15mA, 85 KV.). Image reconstruction was performed using special software (Ondemand 3D version 1.0.9, Cybermed,
Korea.). Radiographic evaluation was focused on bone quantity.

Alveolar crest, original sinus floor and grafted sinus floor were traced and the following measures were recorded in $\mathrm{T}_{0}$ and $\mathrm{T}_{6}$ :

- Residual bone height (R): The distance from the marginal bone crest to the original sinus floor.

- Bone graft height $(\mathrm{G})$ : The distance from the original sinus floor to the new sinus floor.

- Total bone height $(\mathrm{H})$ : The distance from the marginal bone crest to the new sinus floor.

- Bone loss (L): The difference between graft height at immediate and 6-month radiographs $\left(\mathrm{G}_{0}-\mathrm{G}_{6}\right)$.

- The Percentage of bone loss (L\%): The percentage of the bone loss $(\mathrm{L})$ to the bone height of the graft $\left(\mathrm{G}_{0}\right)$.

After a healing period of 6 months, a core biopsy was taken from each sinus and an implant with the suitable length and diameter was selected according to the previous radiographic examination.

A trephine bur with $3 \mathrm{~mm}$ internal diameter was used to obtain a core biopsy from the previously grafted site according to the surgical stent (Figure 3 ). The bone biopsy was then separated and kept in a labeled bottle containing a preservative. After 4 months, the final impressions were obtained and the definitive ceramometal restorations were fabricated and delivered to the patient.

\section{Specimen Processing}

Each core bone biopsy contained both the grafted area and the native alveolar crest of the maxillary sinus floor. Biopsy samples were fixed in $10 \%$ buffered formalin and sent for histological examination. Decalcification of the specimen was obtained by suspension in EDTA $10 \%$ solution for one week with regular renewal of the solution daily. After the decalcification, the specimen dehydrated 


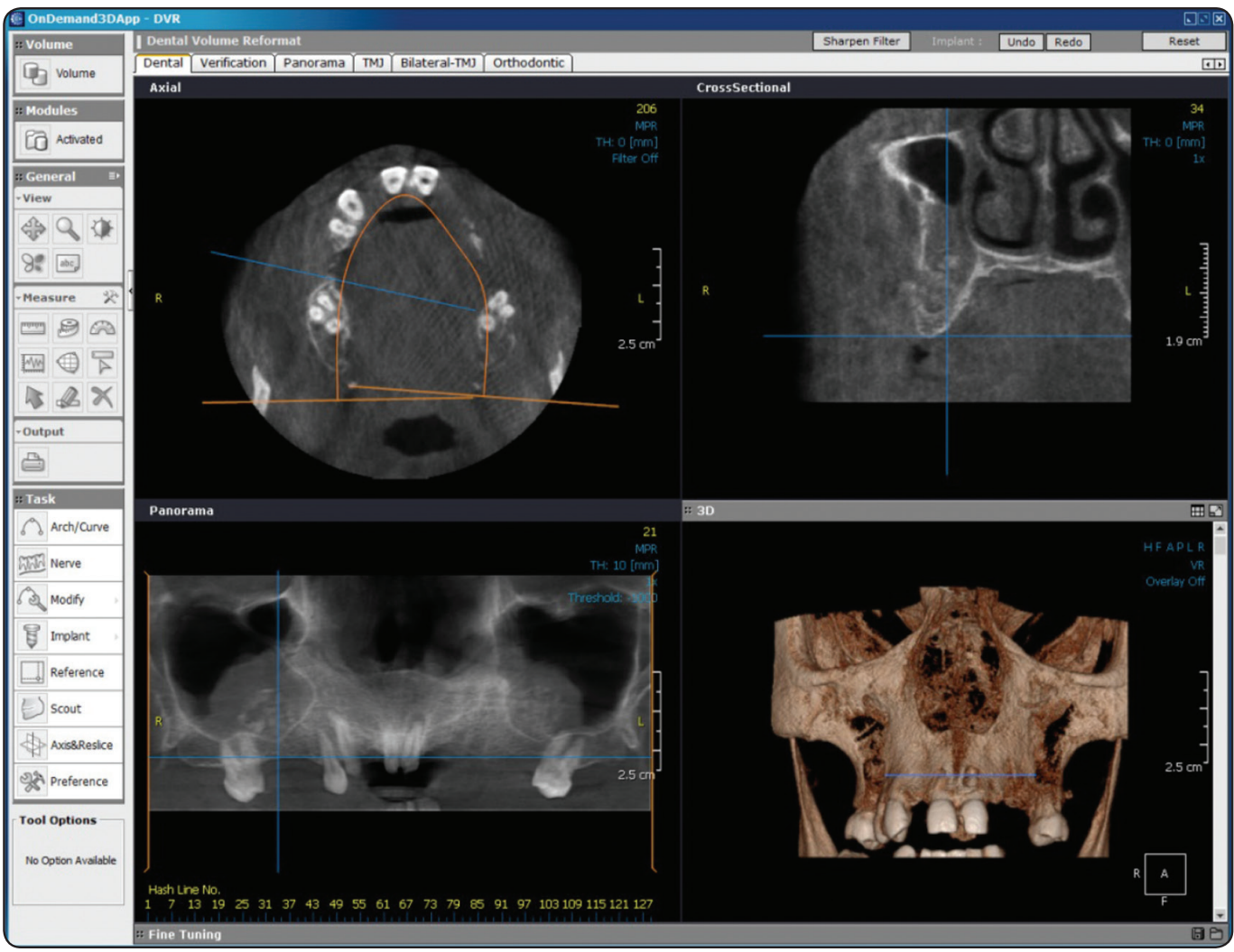

Fig. (1): Cone beam CT 1 week postoperatively

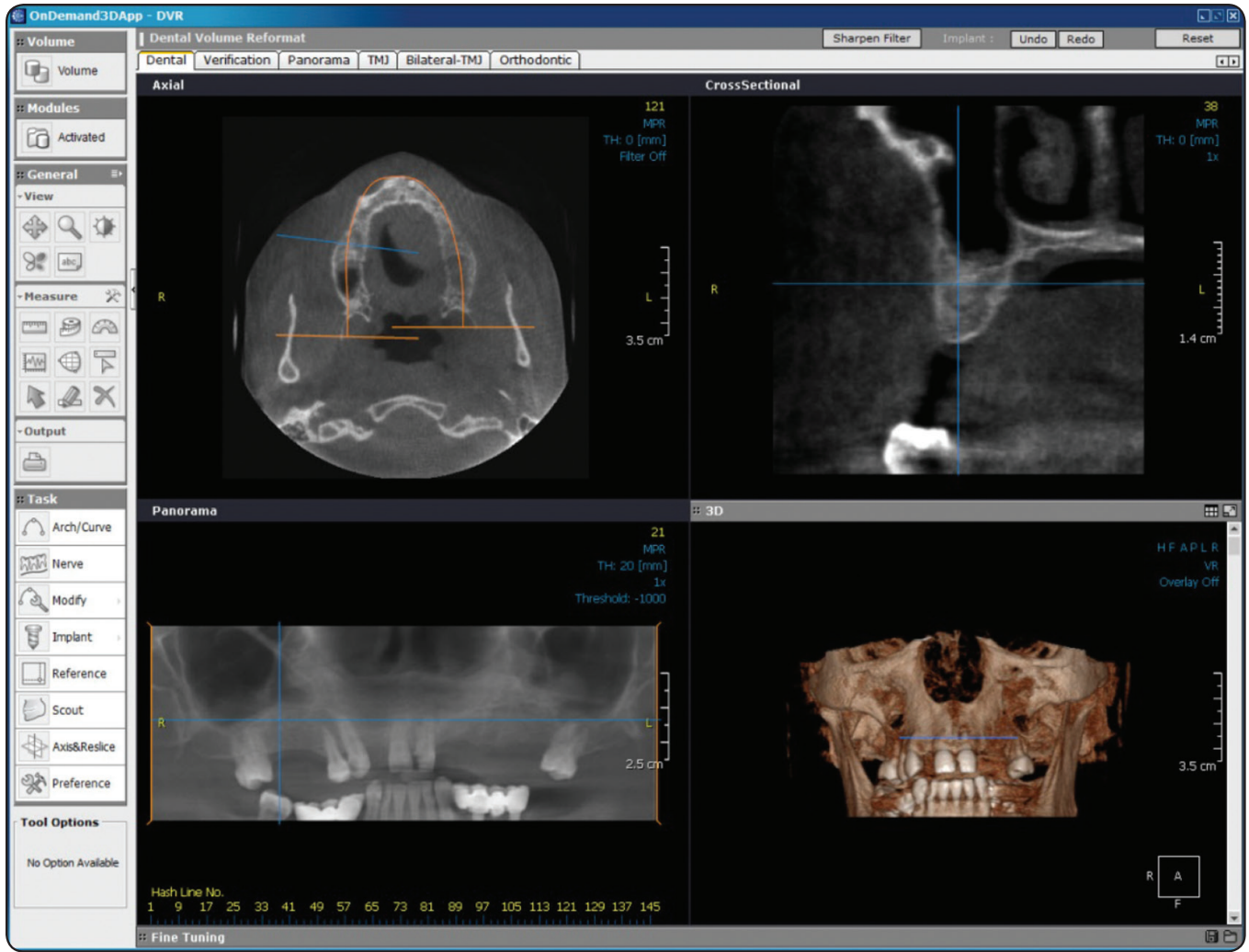

Fig. (2): Cone beam CT 6 months postoperatively 


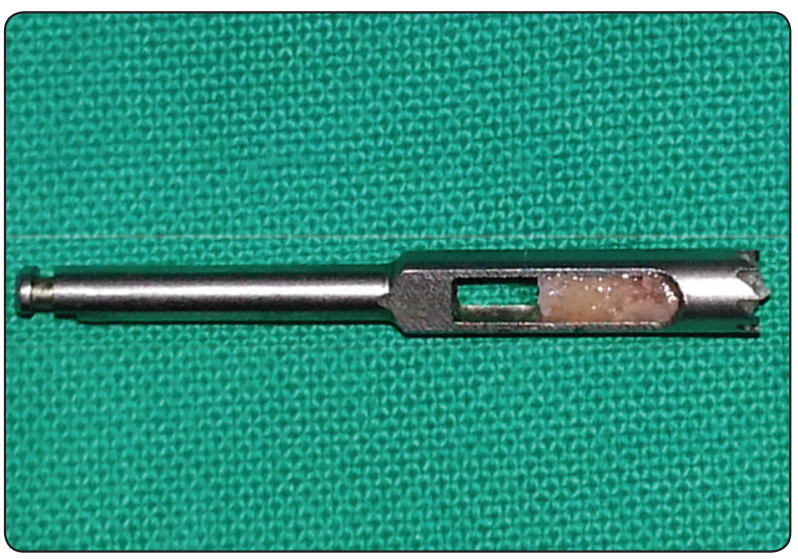

Fig. (3): Core biopsy harvested followed by implant placement after a 6-months healing period.

by using ascending alcohol, followed by clearing in xylol. Then the specimen was embedded in paraffin wax to form a block. The paraffin block was sectioned using a microtome into thin paraffin sections, each of approximately 5 microns thick. Sections were stained using Masson trichrome stain.

\section{Histomorphometric Analysis}

Area of newly formed trabecular bone and remnants of bone substitute as a percentage of the total area was measured at 40 power fields. In masson Trichrome stained samples, mineralized trabecular bone is identified in deep blue, while bone substitute remnants identified in red (Figure $4,5)$.

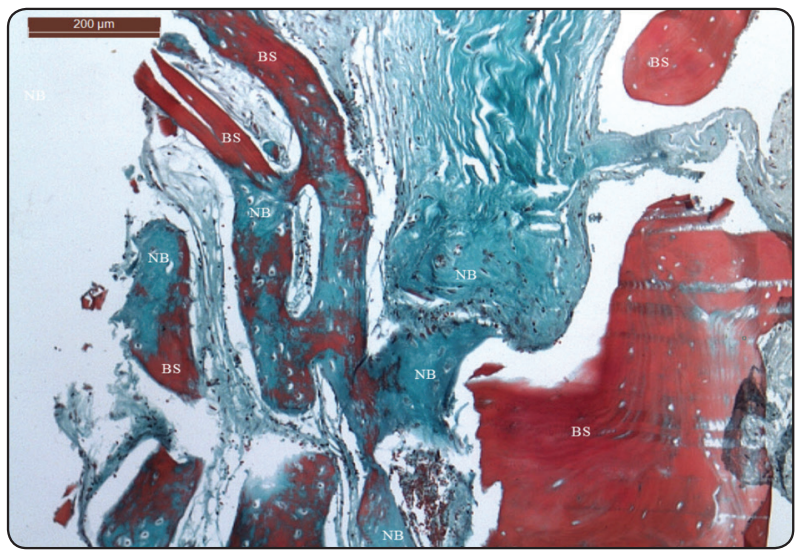

Fig. (4): histomorphometric evaluation of the biopsy section of group A. Mineralized trabecular bone appears deep blue, while xenograft remnants appear red.

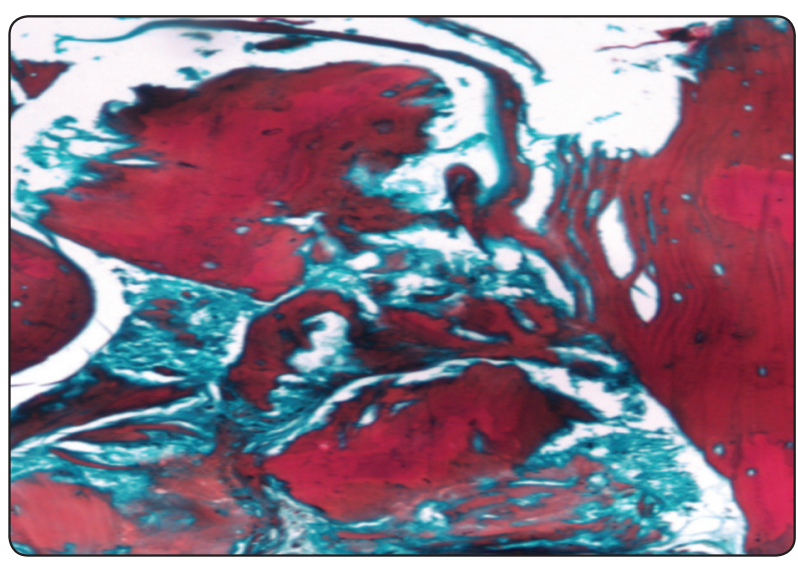

Fig. (5): histomorphometric evaluation of the biopsy section of group B. Mineralized trabecular bone appears deep blue, while $\beta$-TCP remnants appear red.

\section{Statistical analysis}

Statistical analysis was performed using SPSS (Statistical package for the social sciences). The data were represented as mean \pm standard deviation. An Independent sample t-test was used to compare variables between the 2 groups. The results were considered statistically significant if the p- value was less than 0.05 .

\section{RESULTS}

This study was conducted in 12 patients with missing posterior maxillary teeth with insufficient available bone for implant placement indicating the need for maxillary sinus floor augmentation. 12 sinus lifts were performed.

\section{Clinical assessment}

No obvious sinus membrane perforation was observed during the sinus lift procedures. No complications occurred during the healing period of the 2 groups.

\section{Histomorphometric results}

The histomorphometric analysis of samples showed that in group A, the amount of newly formed bone was recorded with an average of 12.4 $\pm 5 \%$; the average of the remaining bone substitute 
TABLE (1) Showing the histomorphometric results of the 2 groups.

\begin{tabular}{|c|c|c|c|c|c|c|}
\hline \multirow{2}{*}{} & \multicolumn{2}{|c|}{ New bone } & \multicolumn{2}{c|}{ Bone substitute } & \multicolumn{2}{c|}{ Connective tissue } \\
\cline { 2 - 7 } & Mean & Std. Deviation & Mean & Std. Deviation & Mean & Std. Deviation \\
\hline Group A & 12.4 & $\pm 5 \%$ & 27.7 & $\pm 10.8 \%$ & 60 & $\pm 11.9 \%$ \\
\hline Group B & 19.5 & $\pm 2.4 \%$ & 26 & $\pm 6.7 \%$ & 54.5 & $\pm 5.8 \%$ \\
\hline
\end{tabular}

was $27.7 \pm 10.8 \%$; while the medullary space and connective tissue was $60 \pm 11.9 \%$. For group B, the amount of newly formed bone was recorded with an average of $19.5 \pm 2.4 \%$; the average of the remaining bone substitute was $26 \pm 6.7 \%$; while the medullary space and connective tissue was $54.5 \pm$ $5.8 \%$ (Table 1).

\section{Newly formed bone}

The mean value of newly formed bone was higher in group B compared to group A. There was statistically significant difference between both groups (table 2).

TABLE (2)

\begin{tabular}{|c|c|c|c|}
\hline & Mean & $\begin{array}{c}\text { Std. } \\
\text { Deviation }\end{array}$ & \multirow{2}{*}{ P value } \\
\cline { 1 - 3 } Group A & $12.4 \%$ & 5 & \multirow{2}{*}{0.933} \\
\cline { 1 - 3 } Group B & $19.5 \%$ & 2.4 & \\
\hline
\end{tabular}

\section{RADIOGRAPHIC EVALUATION:}

Analysis of cone beam CTs showed the following results:

\section{Mean bone height:}

The mean values of different measures in the 2 groups are reported in the following table (table 3 ).
TABLE (3)

\begin{tabular}{|c|c|c|}
\hline & Group A & Group B \\
\hline $\begin{array}{c}\text { Residual bone height } \\
(\mathbf{R})\end{array}$ & $5.31 \pm 1.8 \mathrm{~mm}$ & $5.76 \pm 1.1 \mathrm{~mm}$ \\
\hline $\begin{array}{c}\text { Total bone height after } \\
\mathbf{1} \text { week }\left(\mathbf{H}_{\mathbf{0}}\right)\end{array}$ & $18.97 \pm 2.49 \mathrm{~mm}$ & $17.7 \pm 3.6 \mathrm{~mm}$ \\
\hline $\begin{array}{c}\text { Total bone height after } \\
\mathbf{6} \text { months }\left(\mathbf{H}_{\mathbf{6}}\right)\end{array}$ & $16.95 \pm 2.09 \mathrm{~mm}$ & $16.6 \pm 4.03 \mathrm{~mm}$ \\
\hline $\begin{array}{c}\text { Bone graft height after } \\
\mathbf{1} \text { week }\left(\mathbf{G}_{\mathbf{0}}\right)\end{array}$ & $13.66 \pm 3.5 \mathrm{~mm}$ & $11.93 \pm 3.35 \mathrm{~mm}$ \\
\hline $\begin{array}{c}\text { Bone graft height after } \\
\mathbf{6} \text { months }\left(\mathbf{G}_{\mathbf{6}}\right)\end{array}$ & $11.64 \pm 3.3 \mathrm{~mm}$ & $10.8 \pm 3.8 \mathrm{~mm}$ \\
\hline
\end{tabular}

\section{Percentage of bone loss:}

Group A showed higher bone loss compared to group B, there was a statistical significant difference between both groups (table 4).

TABLE (4) Showing the average percentage of bone loss in both groups.

\begin{tabular}{|c|c|c|c|}
\hline & Mean & $\begin{array}{c}\text { Std. } \\
\text { Deviation }\end{array}$ & \multirow{2}{*}{ P value } \\
\cline { 1 - 3 } Group A & $15.02 \%$ & 8.5 & \multirow{2}{*}{0.646} \\
\hline Group B & $10.49 \%$ & 7.12 & \\
\hline
\end{tabular}




\section{DISCUSSION}

This study was conducted to evaluate bone quality and quantity by using different graft materials for maxillary sinus augmentation histologically and histomorphometrically and implant placement. An ideal maxillary sinus bone grafting material should provide biologic stability, volume maintenance, and allow the occurrence of new bone formation and bone remodeling. ${ }^{(33)}$ The most important factor influencing reduction in vertical bone height by time after sinus augmentation is the grafting material, followed by the presence of a functional implant. ${ }^{(34)}$

In group A, the xenograft (Tutobone) packed in the sinus cavity under the lifted membrane while for group B, the $\beta$-TCP packed in the sinus cavity under the lifted membrane especially in the posterior and anterior parts.

Histological evaluation of the newly formed tissues in sinus augmentation procedures will be helpful in understanding issues like the nature and amount of newly formed bone and the grafting material that remains. Complete resorption of the bone graft, which is to be replaced by new bone at a later stage, is preferable. ${ }^{(35)}$

At the time of implant insertion, the histological evaluation of the core biopsy for group A and B revealed that the presence of newly formed irregular osteoid bone trabeculae rimmed by osteoblasts is higher in group B compared to group A and we also found that Group A showed higher bone loss compared to group B. These findings were emphasized by Zerbo et al. ${ }^{(36)}$ that reported that in sinus floor elevation, the first few $\beta$-TCP particles, lying directly over the residual or original bone of the maxilla, were often partially or even completely replaced by bone after 6 months. The particles of $\beta$-TCP more apical to these were progressively less infiltrated or surrounded by bone. This slow rate of resorption allows the $\beta$-TCP to act as a scaffold for new bone formation.
The second primary outcome of this study was the volumetric stability of the graft. Volumetric stability is mainly affected by the grafting material type followed by the presence of functional implant. While the particles size showed no or minimal effect on changes of sinus graft height. Anorganic bovine xenograft showed minor or no changes in bone height when compared to $\beta$-TCP particles ${ }^{(37,38)}$.

However, there is some controversy regarding the xenograft resorption and new bone formation. Many authors consider that due to its slow resorption, it is a long-lasting material. On the other hand, some authors think that this long-term stability avoids undesirable bone volume resorption due to the bone remodeling process ${ }^{(16)}$.

\section{CONCLUSIONS}

This study showed that $\beta$-TCP showed superior bone quality and quantity compared to bovine xenograft in case of open sinus augemntation. However, with our study, we may confirm that different grafting materials can be safely used, and, depending on the preference of the clinician. In each case, selection of the appropriate biomaterial has to be performed considering advantages and disadvantages, and keeping in mind that we may expect predictable results and clinical success.

\section{REFERENCES}

1. Heinemann F, Mundt T, Biffar R, Gedrange T, Goetz W.: A 3-year clinical and radiographic study of implants placed simultaneously with maxillary sinus floor augmentations using a new nanocrystalline hydroxyapatite. J Physiol Pharmacol; Suppl 8: 91-97, 2009.

2. Misch C.E. (ed): Maxillary sinus anatomy, pathology and graft surgery. In: Contemporary implant dentistery, $3^{\text {rd }}$ edition. Mosby, Elsevier. Pp 905-974, 2008.

3. Maiorana C, Brivio P, Beretta M, Grossi GB, Cicciu M.: Five years of clinical and radiographical evaluation of implant survival and dimensional stability of maxillary sinus augmentation procedures performed with plateletrich plasma. J Dent Implant; 1: 42-50, 2011. 
4. Pelo S, Gasparini G, Moro A, Boniello R, Amoroso PF: Segmental Le Fort I osteotomy with bone grafting in unilateral severely atrophied maxilla. Int J Oral Maxillofac Surg; 38: 246-249, 2009.

5. Munoz-Guerra MF, Naval-Gias L, Capote-Moreno A: Le Fort I osteotomy, bilateral sinus lift, and inlay bone-grafting for reconstruction in the severely atrophic maxilla: a new vision of the sandwich technique, using bone scrapers and piezosurgery. J Oral Maxillofac Surg; 67: 613-618, 2009.

6. Chiapasco M, Casentini P, Zaniboni M: Bone augmentation procedures in implant dentistry. Int J Oral Maxillofac Implants; Suppl 24: 237-259, 2009.

7. Tatum OH: Maxillary and sinus reconstruction. Dent Clin North Am; 30: 207-229, 1986.

8. Farré-Pagés N, Augé-Castro ML, Alaejos-Algarra F, Mareque-Bueno J, Ferrés-Padró E, Hernández-Alfaro F: A novel trephine design for sinus lift lateral approach. Case report. Med Oral Patol Oral Cir Bucal; 16: e79-82, 2011.

9. Kim YK, Yun PY, Kim SG, Lim SC: Analysis of the healing process in sinus bone grafting using various grafting materials. Oral Surg Oral Med Oral Pathol Oral Radiol Endod; 107(2): 204-211, 2009.

10. Handschel J, Simonowska M, Naujoks C, Depprich RA, Ommerborn MA, Meyer U, Kübler NR: A histomorphometric meta-analysis of sinus elevation with various grafting materials. Head Face Med; 5:12, 2009.

11. Nkenke E, Stelzle F: Clinical outcomes of sinus floor augmentation for implant placement using autogenous bone or bone substitutes: a systematic review. Clin Oral Implants Res; 20 (Suppl 4): 124-133, 2009.

12. Rickert D, Slater JJ, Meijer HJ, Vissink A, Raghoebar GM: Maxillary sinus lift with solely autogenous bone compared to a combination of autogenous bone and growth factors or (solely) bone substitutes. A systematic review. Int J Oral Maxillofac Surg; 41(2):160-167, 2012.

13. Iezzi G, Degidi M, Piattelli A, Mangano C, Scarano A, Shibli JA, Perrotti V: Comparative histological results of different biomaterials used in sinus augmentation procedures: a human study at 6 months. Clin Oral Implants Res; 23(12): 1369-1376, 2012.

14. Scarano A, Degidi M, Iezzi G, Pecora G, Piattelli M, Orsini G, Caputi S, Perrotti V, Mangano C, Piattelli A: Maxillary sinus augmentation with different biomaterials: a comparative histologic and histomorphometric study in man. Implant Dent; 15(2): 197-207, 2006.

15. Pettinicchio M, Traini T, Murmura G, Caputi S, Degidi M, Mangano C, Piattelli A: Histologic and histomorphometric results of three bone graft substitutes after sinus augmentation in humans. Clin Oral Investig; 16(1): 45-53, 2012.

16. Martinez A, Franco J, Saiz E, Guitian F: Maxillary sinus floor augmentation on humans: Packing simulations and 8 months histomorphometric comparative study of anorganic bone matrix and $\beta$-tricalcium phosphate particles as grafting materials. Mater Sci Eng C Mater Biol Appl; 30(5): 763-769, 2010

17. Jensen OT (ed): Use of xenografts for sinus augmentation. In: The sinus bone graft, $2^{\text {nd }}$ edition. Quintessence Publishing Co, Inc. Pp 211-219, 2006.

18. Hallman M, Thor A: Bone substitutes and growth factors as an alternative/complement to autogenous bone for grafting in implant dentistry. Periodontol 2000; 47: 172-192, 2008.

19. Wheeler SL.: Sinus augmentation for dental implants: the use of alloplastic materials. J Oral Maxillofac Surg. 55(11):1287-93, 1997.

20. Jensen OT, Shulman LB, Block MS, Iacono VJ.: Report of the Sinus Consensus Conference of 1996. Int J Oral Maxillofac Implants. 13.11-45, 1998

21. Bucholz, R.W.: Nonallograft osteoconductive bone graft substitutes. Clinical Orthopedics and Related Research 395: 44-52, 2002.

22. LeGeros, R.Z.: Properties of osteoconductive biomaterials: calcium phosphates. Clinical Orthopaedics and Related Research. 395: 81-98, 2002.

23. Zerbo IR, Zijderveld SA, de Boer A, Bronckers ALJJ, de Lange G, ten Bruggenkate CM, Burger EH.: Histomorphometry of human sinus floor augmentation using a porous b-tricalcium phosphate: a prospective study. Clin. Oral Impl. Res. 15, 724-732, 2004.

24. Ogose A, Kondo N, Umezu H, Hotta T, Kawashima H, Tokunaga K.: Histological assessment in grafts of highly purified beta-tricalcium phosphate (OSferion) in human bones. Biomaterials .27:1542-9, 2006.

25. Damien CJ, Parsons JR. Bone graft and bone graft substitutes.: A review of current technology and applications. J Appl Biomater. 2:187-208, 1991. 
26. Hollinger JO, Brekke J, Grunskin EG, Lee D.: Role of bone substitutes. Clin Orthop. 324:55-65, 1996.

27. Ohgushi H, Goldberg VH, Caplan AI.: Heterotopic osteogenesis in porous ceramic induced by marrow cells. J Orthop .7:568-79, 1989.

28. Ohgushi H, Okumura M, Tamai S, Shors ES, Caplan AI.: Marrow cell induced osteogenesis in porous hydroxyapatite and tricalcium phosphate. J Biomed Mater Res. 24:1563-70, 1990

29. St John KR, Zardiackas LD, Terry RC, Teasdall RD, Cooke SE.: Histological and electron microscopic analysis of tissue response to synthetic composite bone graft in the canine. J Appl Biomater. 6:89-97, 1995.

30. Zerbo IR., A. L. Bronckers.: "Localization of osteogenic and osteoclastic cells in porous beta-tricalcium phosphate particles used for human maxillary sinus floor elevation." Biomaterials 26(12): 1445-1451, 2005.

31. Yokozeki H, Hayashi T, Nakagawa T.: Influence of surface microstructure on the reaction of the active ceramics in vivo. J Mater Sci Mater Med. 9(7):381-384, 1998.

32. Simunek A, Kopecka D, Somanathan RV.: Deproteinized bovine bone versus beta-tricalcium phosphate in sinus augmentation surgery: a comparative histologic and histomorphometric study. Int J Oral Maxillofac Implants. 23(5):935-942, 2008.

33. Kim YK ${ }^{1}$, Yun PY, Kim SG, Lim SC.: Analysis of the healing process in sinus bone grafting using various grafting materials. Oral Surg Oral Med Oral Pathol Oral Radiol Endod. 107(2):204-11, 2009.
34. Mardinger $\mathrm{O}^{1}$, Chaushu G, Sigalov S, Herzberg R, Shlomi B, Schwartz-Arad D.: Factors affecting changes in sinus graft height between and above the placed implants. Oral Surg Oral Med Oral Pathol Oral Radiol Endod. 111(1):6$11,2011$.

35. Artzi, Z., Weinreb, M., Givol, N., Rohrer, M.D., Nemcovsky, C.C., Prasad, H.S. \& Tal, H.: Biomaterial resorption rate and healing site morphology of inorganic bovine bone and beta-tricalcium phosphate in the canine: a $24-$ month longitudinal histologic study and morphometric analysis. International Journal of Oral and Maxillofacial Implants 19: 357-368, 2004.

36. Zerbo IR, Zijderveld SA, de Boer A, Bronckers AL, de Lange G, ten Bruggenkate CM, Burger EH: Histomorphometry of human sinus floor augmentation using a porous beta-tricalcium phosphate: a prospective study. Clinical Oral Implants Research. 15:724-732, 2004.

37. Chackartchi T, Iezzi G, Goldstein M, Klinger A, Soskolne A, Piattelli A, Shapira L: Sinus floor augmentation using large (1-2 mm) or small $(0.25-1 \mathrm{~mm})$ bovine bone mineral particles: a prospective, intra-individual controlled clinical, micro-computerized tomography and histomorphometric study. Clin Oral Implants Res; 22(5): 473-480, 2011.

38. Mardinger O, Chaushu G, Sigalov S, Herzberg R, Shlomi B, Schwartz-Arad D: Factors affecting changes in sinus graft height between and above the placed implants. Oral Surg Oral Med Oral Pathol Oral Radiol Endod; 111(1): e611,2011 . 